\title{
The Teaching Innovation Research of Electron Microscope
}

\author{
Qian Li, Wenli Zhang, Yemin Liu \\ Medical research center, Hebei United University, Thangshan, China \\ 340154235@qq.com
}

\begin{abstract}
In order to improve the teaching quality of electron microscope, Pays great attention to the student interest and the innovation ability appraisal in the teaching, strengthened the electron microscope teaching reform and the construction raise, guided and driven student's medicine scientific research power of thought.

Index Terms - Electron Microscope, Teaching, quality
\end{abstract}

\section{Introduction}

In order to promote reform of teaching of electron microscopes, improve the quality of education and promoting teaching management, the electron microscope room of medical research center gradually explore a series of electron microscopy innovative approaches to teaching, and fundamentally improve the quality of teaching.

\section{Strengthen the hardware facilities to improve the} teaching conditions of electron microscopy

With the rapid development of modern life sciences, electron microscopy has become an indispensable tool of scientific research in the field of biomedical, therefore, improving the quality of teaching of medical schools electron microscopy, also has a very important practical significance to improve the practical ability of undergraduates. In order to improve the experimental teaching environment, to ensure the quality of teaching, the institute in the funds intense situation, in 2005 invested 1.5 million Yuan to purchase a Hitachi H7650 electron microscope newly, applied in the electron microscope teaching of scientific research and undergraduate student, and necessary newly-built laboratory and auxiliary housing. The university has also carried on the transformation and the renovation to the old electron microscope room, causes undergraduate student's electron microscope teaching environment and the teaching condition has the further improvement.

\section{In the teaching of electron microscopy, cultivating students ' ability of micro- thinking}

Ultrastructure is significant difference from the structure of the organization under the light microscope, because the students lacked the perceptual knowledge to the ultrastructure, under existing condition, although can help the students to enter the biomedicine ultra microcosm domain, but cannot cause them actually to obtain the solid profound ultramicro morphology knowledge. Before the test we request the students to consult the organization embryology, the cytobiology related content, simultaneously gives the students to distribute from arrange Medical Electronic Microscopy Experiment Instruction, like this makes the student to understand the elementary theory knowledge in front of the observation microstructure. In the experimental class, the purpose of the experiment is more explicit, more targeted experiments, observed ultrathin sections of the normal structure of the cell membrane, nucleus, mitochondria, lysosomes and photos in the grouping of students have achieved good teaching results.

\section{Strengthens the electron microscope teaching, enhances the student to participate in the self- consciousness and initiative of experiment}

The medicine electron microscopy is an institute optional course, the proportion of theory and experiment class hour is $5: 1$. We changed the previous question for single papers, increased the examination of experiment results accounted for a total of $20 \%$, experimental class students hands-on and on electron micrographs of the observation and understanding based on the evaluation results. Theory and experiment are all qualified to obtain the appropriate credit, increased consciousness of the students participating in the experiments and initiatives. After the inspection had ended, the investigation showed that the majority of schoolmate teaching way expressed the support, we also hope that in the future teaching, expanding the depth and breadth of the experimental teaching content, make electron microscopy Teaching more perfect [1].

\section{Unifies the clinical case of illness, stimulate students ' enthusiasm for learning medical knowledge}

Electron microscopy ultrastructural diagnosis can solve some of the problems in the clinical, we have provided the massive source material for the clinician in many years of electron microscope observations, we collected many of the typical significance of clinical electron microscopic photographs to apply in the teaching. For example: we use the pathological change degree and kidney of TEM observation clinical critically ill myasthenia patient to put on the biopsy, hypophysis lump and other cases. Give students a simple introduction actual patient's symptoms and signs, to make students more profound understanding of the course content, both to understand the power mirror technology and medicine of contact and understanding to the unique role of electron microscopy in the etiology of disease, tumor diagnosis and identification of diagnostic, enhanced electron microscopy study interest and inspired students ' enthusiasm for learning medical knowledge[2]. This teaching method is easy to make sense of accomplishment of the students apply their knowledge, broaden their knowledge, broaden their clinical 
research ideas and lay a good foundation for the future engaged in basic and clinical practice.

\section{Standardizing the teaching management and improving the teaching quality}

The teaching management cannot leave the teaching document and teaching rules and regulations consummation, we focus on the assessment of the students' interest and ability to innovate in teaching, medical research to guide and inspire students thinking ability, gradually standardize the teaching management, and constantly improve the quality of teaching, promote the teaching reform and construction of electron microscopy, to optimize the teaching content, creating a new teaching situation.

\section{References}

[1] Huidan Zhang, Jin Fang, et al, Medical detection undergraduate course electron microscope technology class time-limited educational model analysis, Educational Reform, vol. 6, no. 2, pp. 387, 2005

[2] Li Han, Shuming Zhao, Experimental teaching experience of medical electron microsconiversity, Journal of Chengde Medical University, vol. 23, no. 4, pp. 437, 2006. 